\title{
PROCESS PARAMETERS OPTIMIZATION FOR PRODUCING AA6061/TiB 2 COMPOSITES BY FRICTION STIR PROCESSING
}

\author{
SANTHA RAO Dakarapu ${ }^{1}$, RAMANAIAH Nallu ${ }^{2}$ \\ ${ }^{I}$ BVC Engineering college, Faculty of Mechanical Engineering, Odalarevu -533210, Andhra Pradesh, India, \\ email: dsantharao@gmail.com \\ ${ }^{2}$ Andhra university college of Engineering (A), Faculty of Mechanical Engineering, Andhra University, \\ Visakhapatnam- 530003, Andhra Pradesh, India, email: n.rchetty1@gmail.com
}

\begin{abstract}
Friction stir processing (FSP) is solid state novel technique developed to refine microstructure and to improve the mechanical properties and be used to fabricate the aluminium alloy matrix composites. An attempt is made to fabricate $\mathrm{AA} 6061 / \mathrm{TiB}_{2}$ aluminium alloy composite (AMCs) and the influence of process parameters like rotational speed, transverse feed, axial load and percentage reinforcement on microstructure and mechanical properties were studied. The microstructural observations are carried out and revealed that the reinforcement particles $\left(\mathrm{TiB}_{2}\right)$ were uniformly dispersed in the nugget zone. The Tensile strength and Hardness of composites were evaluated. It was observed that tensile strength, and hardness were increased with increased the rotational speed and percentage reinforcement of particles. The process parameters were optimized using Taguchi analysis (Single Variable) and Grey analysis (Multi Variable). The most influential parameter was rotational speed in single variable method and multi variable optimization method. The ANOVA also done to know the percentage contribution of each parameter
\end{abstract}

KEYWORDS: Friction stir processing, Titanium Di boride, Tensile strength, Hardness, Metal Matrix Composite, Taguchi and Grey Analysis.

\section{Introduction}

Aluminium Alloys are widely used in automotive, aerospace and ship building industries due to good strength to weight ratio and better corrosion resistance but they exhibit inferior tribological properties [1]. Aluminium metal matrix composites (AMCs) are widely replacing conventional aluminium alloys in many applications due to superior mechanical properties and tribological properties [2,3]. Extensive Research has been carried out to enhance the properties of AMCs using novel fabrication methods and reinforcements can be the ceramic particles, whiskers and fibers of various types. The commonly used reinforcements include $\mathrm{Sic}, \mathrm{Al}_{2} \mathrm{O}_{3}$, Tic, CNT, Sio $2, \mathrm{~B}_{4} \mathrm{C}$, Fly Ash, Tion, Graphite, SiC etc. [4, 5, 6]. Among the various reinforcements titanium di - boride (TiB2) is of much interest due to its excellent stiffness, hardness and wear resistance. The Aluminium metal matrix composites are produced by liquid metallurgy route such as conventional stir casting and electromagnetic stir casting $[7,8]$. Squeeze casting [9, 10]. and Compo casting [11]. Pressure Infiltration [12, 13], Laser melt injection [14], In situ method [15]. It is difficult to mix reinforcement to molten aluminium and keep it in suspension due to the poor wettability of both matrix and reinforcement [16]. The reinforcement particle tends to react wit1 matrix material in molten state or decompose at higher temperatures to form undesirable compounds which deteriorates the properties of metal matrix composites. Though liquid metallurgy routes are economical for mass production, the homogeneous distribution of reinforcement particles in the casting is a challenge $[17,18]$. The Mixing process of matrix materials and reinforcements in powder metallurgy methods is time consuming, high expensive, energy consuming and it is difficult to obtain a bulk material with 
high density [19]. The process parameters influence the solidification structure of AMCs that demands precise control.

The Friction stir processing (FSP) is modification of FSW techniques which refines the microstructure and improves the mechanical properties [20]. Further produces a homogeneous distribution of reinforcement particles in the aluminium matrix depending upon the process parameters employed and refines the grains [21]. The process is environmentally clean technology as it does not produce any fumes and harmful gases and noise like in other conventional techniques as process can be done in solid state itself. The temperatures developed during the FSW and FSP was below the melting point of material to be processed which avoids interfacial reactions and avoids defects like pin hole porosity, air inclusions. The FSW threedimensional model for $\mathrm{Al}$ alloy was developed and validated by researchers to build up the qualitative parameters $[22,23]$.

Recently, FSP was emerged as novel technique to fabricate metal composites [24] and is based on the FSW.The FSW was derived from concept of friction welding process [25]. In the FSP process, the aluminium alloys metal matrix composites in the solid state itself. At first, the groove or small holes are made in the plates (Fig 1a) and reinforcement particles are packed in the groove (Fig 1b) and compacted with pin less tool ( Fig 1c). Finally tool pin was plunged at one end of plate and transversed over the groove (Fig $1 \mathrm{~d}$ ). The shoulder touches the surface of plate while moving over the groove which produces frictional heat, plasticized the material and the tool pin stirs and mixes the reinforcement with the matrix material and thus produces the composites. Extensive research has been carried out in metal matrix composites and surface composites of aluminium alloys using FSP. The Al 5083 based surface composite via FSP and reported the uniform distribution of reinforcement in the stir zone and good bonding properties between reinforcement and matrix material. The tribological studies showed that surface composite has the highest wear resistance and hardness [26].

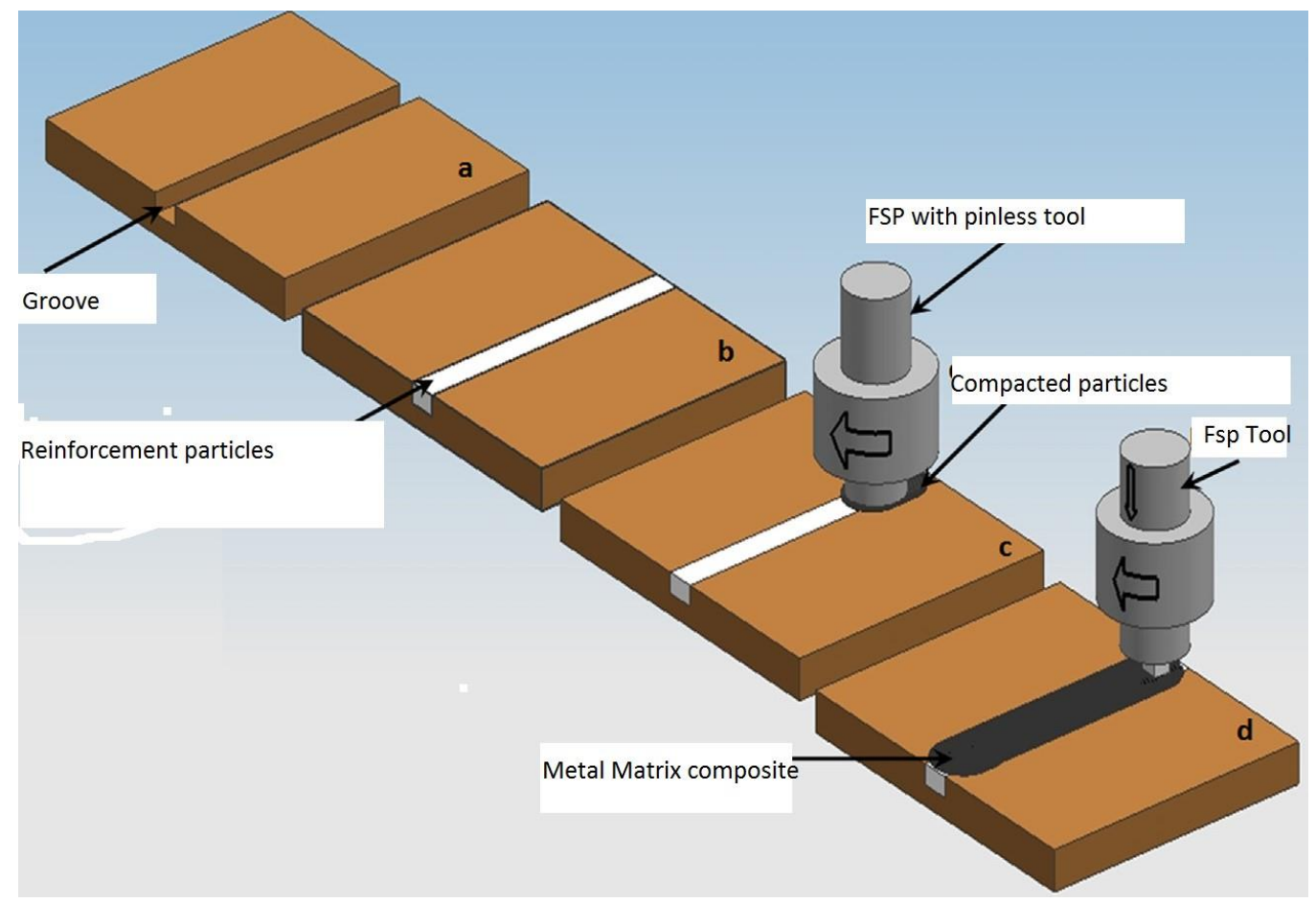

Fig. 1 Basic FSP process

A. Dolatkhah et al [27] fabricated metal matrix composite via FSP and reported the more homogeneous dispersion of particles and fine equiaxed grains in the stir zone and improved 
hardness up to $55 \%$ and wear rate of composite has reduced to 9.7\%. J. Gandra et al [28] fabricated the AA5083/Sic AMC using FSP and studied the effect of groove offset on the distribution of ceramic particles. Adam Kurt et al [29] fabricated composite by incorporating Sic particles into the pure aluminium to form particulate surface layers and reported more uniform distribution of particles with increasing rotational speeds and transverse feeds. Also, found improvement of hardness three times and bending strength significantly higher as compared to base metal. S.R. Anvari et al [30] investigated wear properties of AA6061/Al-CrO hybrid nano composites produced by FSP and showed improved wear resistance of composite sample due to homogeneous dispersion of ceramic particles. Min Yang et al [31] fabricated nano ceramic particle reinforced composite by incorporating $\mathrm{Al}_{2} \mathrm{O}_{3}$ ceramic particles into the surface of AA6061-T6 alloy plate with multiple pass friction stir processing and reported more uniform distribution of the ceramic particles with increase of number of passes and no interfacial reactions. A. Thangarasu et al [32] has produced the AA6081/Tic composite using FSP with different volume proportions of reinforcement and has found that UTS and Hardness were increased and observed more uniform distribution of particles. Y. Morisada et. al [33] successfully fabricated the fullerene/A5083 composites by FSP and reported that fullerene molecules were dispersed in the AA5083, improved the hardness which was due to pinning effect and reduction of grain size.

Taguchi's method is statical tool used for improving the performance of design problem, processes with respect to cost and time and the number of experiments drastically reduced $[34,35]$. This method is used for analysing the experimental results to establish the best condition for a product or processes, to identify the most influential parameters and to predict optimal response of process parameters. Many researchers like Mahmoud.E.R. I [36] and Wang $\mathrm{W}$ et al [37] were carried out using square and threaded pin profiles with speed range of 800 rpm to $1600 \mathrm{rpm}$ and M .Salehi et al [38] and M.Barmaouz et al [39] were selected the feeds in the range of $40 \mathrm{~m} / \mathrm{min}$ to $160 \mathrm{~m} / \mathrm{min}$ and other parameters load and percentage reinforcement were also selected. The Taguchi method is limited for optimization of single response problems. The other interesting optimization technique is multi-response optimization (Grey Rational Analysis) in which more than one response is taken into account simultaneously to obtain an optimal solution for any problems or process. In Grey Rational Analysis (GRA), the multi response problems are converted to single variable problems and then optimal solutions are obtained. The Grey theory proposed by Deng [40] is useful in solving the problems with poor, insufficient and uncertain information and to analyse the relation between process parameters and responses (GRA).

Many researchers done the lot of work in optimization of FSW of aluminium alloys. K. Jitender et al [41] studied the optimization of process parameters in FSW of AA5083 alloy using taguchi grey analysis and the objective was to find the optimum levels of speed, feed, tilt angle for maximizing UTS, Elongation and Micro Hardness. S. Vijayan et al [42] studied the optimization of process parameters in FSW of aluminium alloy with multiple responses based on orthogonal array using grey relational analysis. The objective was to find the optimum levels of the process parameters in which it yields maximum tensile strength and consumes minimum power. S. Kasman et al [43] studied on multi-response optimization for dissimilar FSW of AA6082- AA5754 alloys optimized tensile strength and elongation using taguchi and grey method and concluded that all parameters were significant. The best parameters were $D / d$ ratio of 4, speed of $1000 \mathrm{rpm}$ and 100 meters per min. Chien et at [44] optimized the FSW of AA5083 and four parameters were optimized by considering minimum cost. The taguchi and grey was optimized towards the optimum tensile strength and elongation. The optimum values were rotational speed of $1800 \mathrm{rpm}$, transverse speed of $180 \mathrm{~m} / \mathrm{min}$, tool tilt angle of $1^{\circ}$ and pin length of $2.9 \mathrm{~mm}$. S. Vijayan et al [45] studied friction stir welding (FSW) of AA 5083 with multiple 
responses based on orthogonal array with grey relational analysis. The process parameters such as speed, feed and axial load were considered and optimized parameters towards high the tensile strength of the joint and input power. N.D. Ghetiya et al [46] studied multi-objective optimization of FSW process parameters of aluminium alloy using Taguchi-based grey relational analysis. The typical process parameters were tool shoulder diameter, rotational speed, welding speed and the axial load for FSW of AA 8011. The multiple-characteristics namely tensile strength, micro hardness and power consumption were optimized.

It was observed from the literature that influence of $\mathrm{TiB}_{2}$ particles on microstructure and mechanical properties of composites by FSP was not reported. Further, many researchers considered only one fixed volume of reinforcement. Hence an attempt was made to fabricate the AA 6061/ $\mathrm{TiB}_{2}$ composite using FSP and investigated the effect of reinforcement particles on micro structure and mechanical properties of composite. The four parameters and four levels were selected and generated $\mathrm{L}_{16}$ matrix using MINI TAB software. The process parameters were optimized using Taguchi method for single responses towards the tensile strength and hardness and multi objective method grey analysis for both responses. The percentage contribution of process parameters was estimated using Analysis of Variance (ANOVA). The optimal process parameters were predicted and validated the model by conducting confirmation experiments.

\section{Experimentation}

The commercially available Aluminium Alloy plates of $6 \mathrm{~mm}$ thick and plates are cut to size of $150 \mathrm{~mm} \times 100 \mathrm{~mm}$. The selected reinforcement is titanium di boride $\left(\mathrm{TiB}_{2}\right)$ powder particles of 99.00 purity and average particle size of $2.0 \mu \mathrm{m}$. The chemical composition and mechanical properties of base metal is presented in the Table 1 and Table 2 . The square grooves of $0.5 \mathrm{~mm}$ $\times 3 \mathrm{~mm}, 0.5 \mathrm{~mm} \times 5.3 \mathrm{~mm}, 1 \mathrm{~mm} \times 4 \mathrm{~mm}$ in size were made on the centre of plate by Wire cut EDM process to accommodate the volume of reinforcement of $0 \%, 4 \%, 8 \%$ and $12 \%$ by volume. The tool is made of HSS and dimensions of the tool pin were diameter of $6 \mathrm{~mm}$ and $5.5 \mathrm{~mm}$ length and threaded pin of $1 \mathrm{~mm}$ pitch. The process parameters and their levels shown in the Table 3. The experimental design matrix is shown in the Table 4. The powder was packed in the groove after clamping the plate on the machine vice. The tool without pin (first tool) was traversed along the groove to compact the particles and to avoid spattering of powder during FSP. The FSP was carried out indigenously developed FSW machine with threaded pin (second tool) tool tilt angle of $2^{\circ}$ was used for all experiments and single pass FSP was used to fabricate the aluminium metal composites (AMCs). The working arrangement of FSP process and composite after experimentation are shown in Fig 2 a and Fig 2 b. The aluminium metal composites were produced with different process parameters as per design matrix L16.

Table 1. Chemical composition of AA 6061 -T6 alloy.

\begin{tabular}{|c|c|c|c|c|c|c|c|c|}
\hline Element & $\mathrm{Mg}$ & $\mathrm{Si}$ & $\mathrm{Fe}$ & $\mathrm{Mn}$ & $\mathrm{Cu}$ & $\mathrm{Cr}$ & $\mathrm{Ti}$ & $\mathrm{Al}$ \\
\hline Wt. \% & 0.825 & 0.711 & 0.342 & 0.023 & 0.152 & 0.017 & 0.083 & balance \\
\hline
\end{tabular}

After FSP, the samples were cut for micro structural examination, tensile strength and hardness of composites. The micro structural observations were carried out at cross section of stir zone (SZ) normal to the FSP direction of composites. The samples were polished mechanically and etched with Keller's Agent $\left(2 \mathrm{ml} \mathrm{HF}, 20 \mathrm{ml} \mathrm{HNO}_{3}\right.$ and $175 \mathrm{ml}$ distilled water. The micro structures were observed by optical microscope and Scanning electron microscope. The tensile specimens were prepared as per the ASTM E-8 standards to the required dimensions which is parallel to the direction of composite shown in Fig 3. The tensile test was conducted on the computer controlled universal testing machine. 


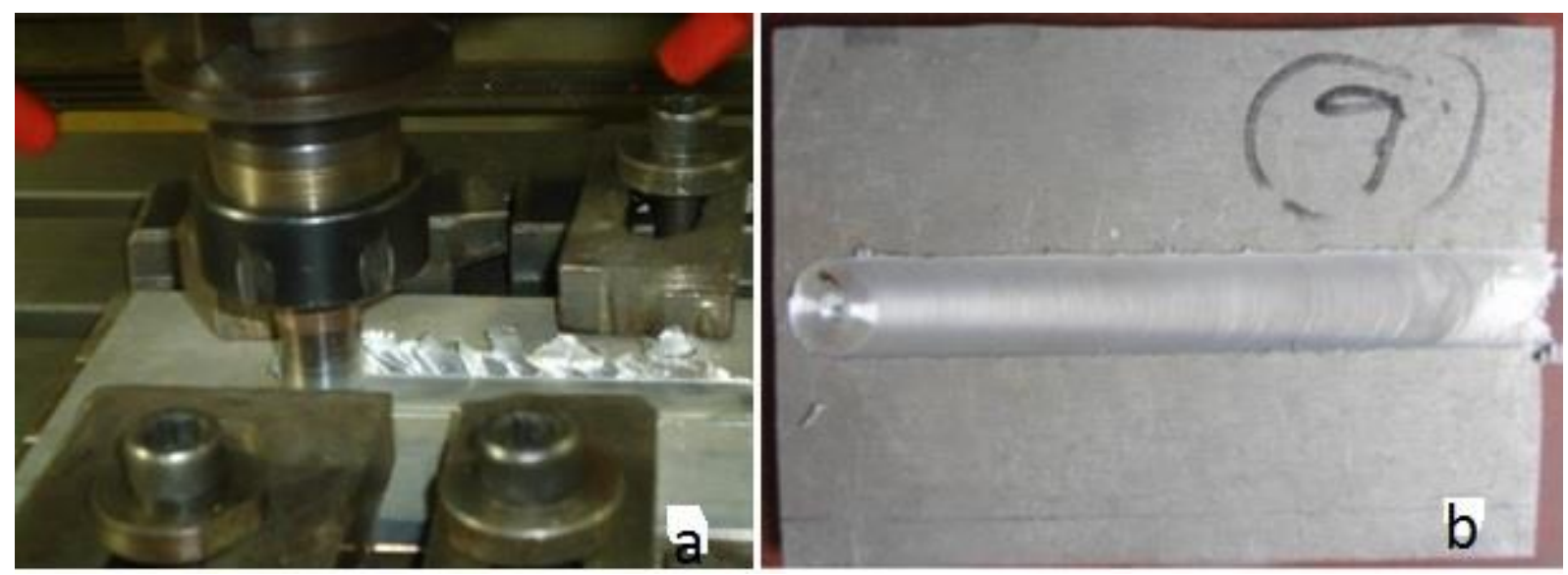

Fig. 2 FSP process and composite a) FSW process b) composite fabricated by FSP

Table 2. Mechanical Properties of Base Metal AA 6061 - T6 alloy

\begin{tabular}{lllll}
\hline $\begin{array}{l}\text { Yield Strength } \\
(\mathrm{MPa})\end{array}$ & $\begin{array}{l}\text { Ultimate } \\
\text { Tensile } \\
\text { Strength(MPa) }\end{array}$ & $\begin{array}{l}\text { Percentage } \\
\text { Elongation (\%) }\end{array}$ & $\begin{array}{l}\text { Vickers } \\
\text { Hardness (Hv) }\end{array}$ & $\begin{array}{l}\text { Impact } \\
\text { strength (J) }\end{array}$ \\
\hline 278 & 310 & 16 & 104 & 23 \\
\hline
\end{tabular}

Table 3. Process Parameters and their Levels

\begin{tabular}{ccccc}
\hline Levels $\rightarrow$ & & 3 & 4 \\
$\begin{array}{c}\text { Process parameter } \\
\downarrow\end{array}$ & 1 & 2 & 1400 & 1700 \\
\hline Speed (rpm) & 800 & 1100 & 60 & 80 \\
Feed (mm/min) & 20 & 40 & 6 & 7 \\
Axial Load(N) & 4 & 5 & 8 & 12 \\
Reinforcement $(\%)$ & 0 & 4 & & \\
\hline
\end{tabular}

Table 4. Taguchi matrix (L16)

\begin{tabular}{ccccc}
\hline Exp. No. & Speed (S) & Feed (F) & Axial Load (L) & $\begin{array}{c}\text { \% } \\
\text { Reinforcement } \\
(\mathbf{R})\end{array}$ \\
\hline $\mathbf{1}$ & & & & 0 \\
$\mathbf{2}$ & 800 & 20 & 4 & 4 \\
$\mathbf{3}$ & 800 & 40 & 5 & 8 \\
$\mathbf{4}$ & 800 & 60 & 6 & 12 \\
$\mathbf{5}$ & 800 & 80 & 7 & 8 \\
$\mathbf{6}$ & 1100 & 20 & 5 & 12 \\
$\mathbf{7}$ & 1100 & 40 & 4 & 0 \\
$\mathbf{8}$ & 1100 & 60 & 7 & 4 \\
$\mathbf{9}$ & 1100 & 80 & 6 & 12 \\
$\mathbf{1 0}$ & 1400 & 20 & 6 & 8 \\
$\mathbf{1 1}$ & 1400 & 40 & 7 & 4 \\
$\mathbf{1 2}$ & 1400 & 60 & 4 & 0 \\
$\mathbf{1 3}$ & 1400 & 80 & 5 & 0 \\
$\mathbf{1 4}$ & 1700 & 20 & 7 & 12 \\
$\mathbf{1 5}$ & 1700 & 40 & 6 & 8 \\
$\mathbf{1 6}$ & 1700 & 60 & 4 & 5 \\
\hline
\end{tabular}


The fractured surface of broken tensile pieces was analysed by SEM to study the nature of fracture and its morphology. The Micro Hardness was measured in the Stir Zone (SZ) using a micro hardness tester with load of 500 Grams and a dwell time of $10 \mathrm{sec}$ at stir zone(SZ). The output responses were tabulated in the Table 5

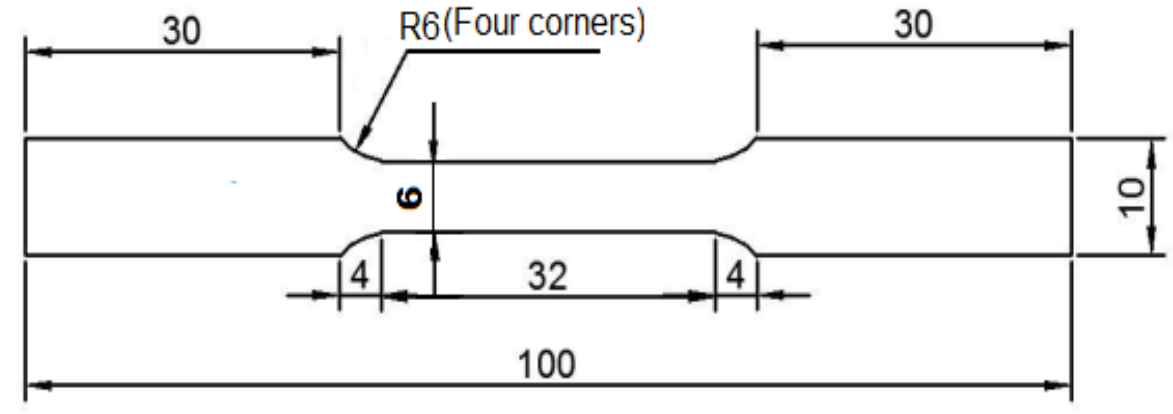

Fig. 3 Tensile specimen as per ASTM- E8 standards

\section{$3 \quad$ Results and discussions}

\subsection{Micro structure}

The optical photo micrographs of all samples including base metal were examined. The fine dark particles widely existed are $\mathrm{Mg}_{2} \mathrm{Si}$ precipitate phase and are elongated coarse grains in the base metal. The Fig 4 a- $d$ and Fig 5 a- $d$ shows the photo micrographs and SEM images of base metal and composites respectively with $0 \%$ reinforcement, Exp. 2 for $4 \%$ reinforcement and Exp.10 for $8 \%$ reinforcement. The composite with $0 \%$ reinforcement has lesser size of grains than the base metal. It was observed that $\mathrm{TiB}_{2}$ particles were uniformly distributed with in the stir zone which were more uniform distribution of reinforcement particles with $8 \%$ composite than $4 \%$ reinforcement. The severe and intense plastic deformation at elevated temperature causes the dynamic crystallization (DRX) which in turn refines the grains responsible for higher hardness and low ductility. The similar observations were found in earlier work of M.M. El Rayes, A. Hamdollahzadeha et al and M. Barmouz et al $[47,48,49]$. The $\mathrm{TiB}_{2}$ particles restrains the movement of grains which in turn reduces the grain growth and causes dynamic crystallization. This is known as pinning effect [32]. The SEM images of Exp 10 and EDS of composites were examined by Scanning Electron Microscope and observed that clear and good interfacial conditions achieved between particles and found no voids and no micro pores. The EDS analysis shows that rich in aluminum and there is loss of other elements like magnesium and silicon during FSP.

\subsection{Mechanical properties}

The mechanical properties such as Ultimate tensile strength, percentage elongation and yields strength and hardness were evaluated and presented in the Table 5. It was observed that UTS increased with increase of speed and volume of reinforcement but decreased ductility due to grain refinement and presence of reinforcement particles in matrix material. The higher value of UTS was observed with increase of speed and reinforcement. This may due to higher the heat input with the higher speed which cause more softening effect in the stir zone because of stirring action of the tool pin. The similar observations were drawn by researchers $[32,29]$. This mighty be due to strengthening mechanisms such as orowan and enhanced dislocation density [50]. It also observed that elongation of composites was less than the base metal due to presence 
of reinforcement particles which may leads to increase of slip distance of dislocations during deformation of material during processing of composites. The tensile fracture surface of the base metal and friction stir processed composites of the tensile test specimens were characterized by using scanning electron microscope to understand the failure pattern. The fracture surface morphology of samples consists of dimples which are shown in Fig 6 a - c for base metal, Exp 2 and Exp 10 respectively. The deeper and lower dimples were observed for Exp 1 which is indicative of lower UTS and high ductility whereas shallow and larger dimples for experiment 10 which is indicative of higher UTS and low ductility.

The micro hardness of all samples in the SZ were presented in Table 5. All composites samples have higher hardness. The highest value of Hardness of $129.137 \mathrm{HV}$ which $24.17 \%$ higher than the base metal and found increased with increase of speed and reinforcement. The similar results were reported by researchers A. Thangarasu et al [32] and L. Suvarna Raju et al [51]. This may be due to presence of reinforced particles and micro structural changes like DRX induced by FSP and orowan strengthening and the movement of dislocations due to presence of reinforcement are responsible for improvement of hardness.
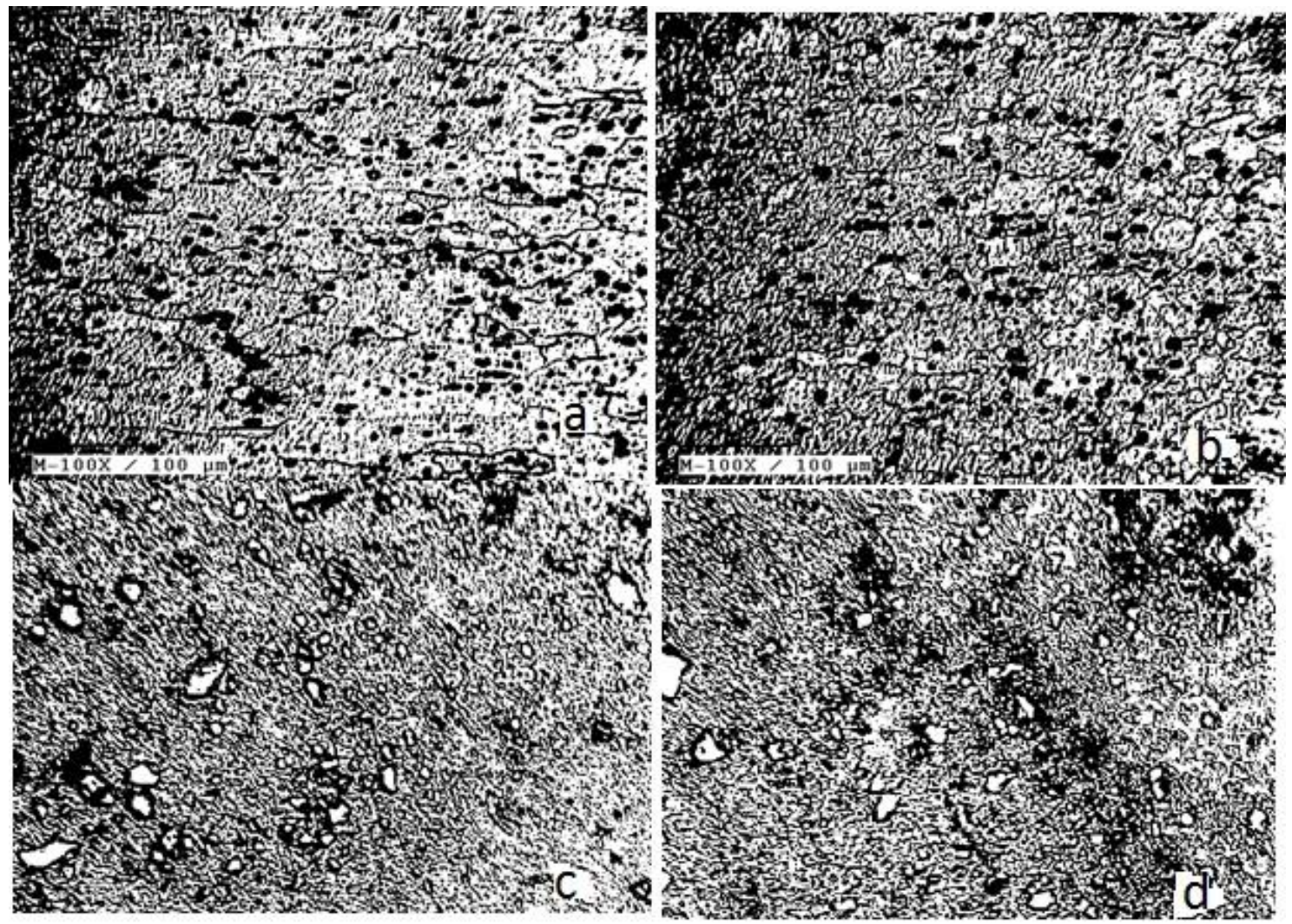

Fig. 4 Micro structure of a) Base metal b) Experiment 1 (0\% reinforcement) c) Experiment 2 (4\% reinforcement) d) Experiment 10 (8\% reinforcement) 

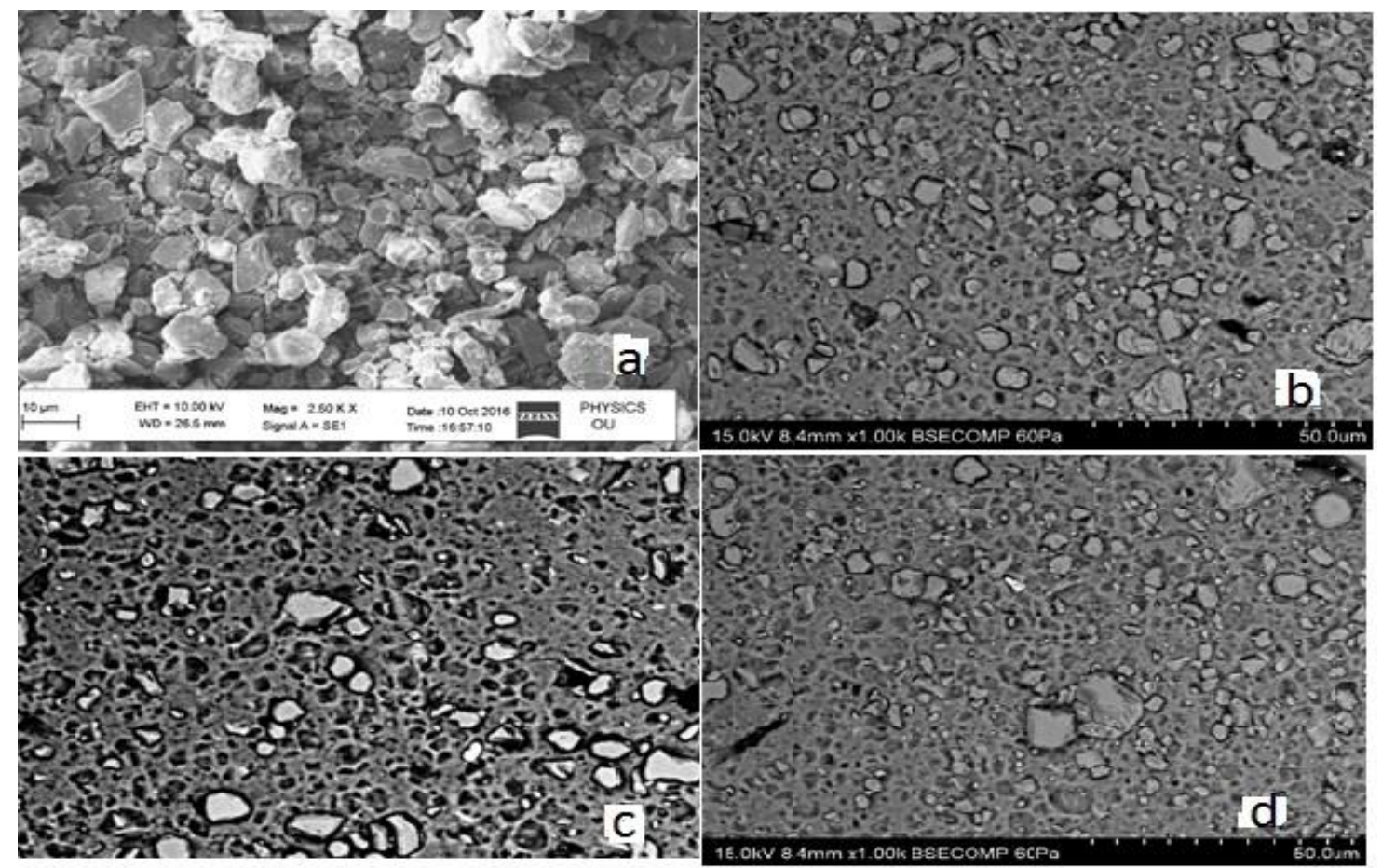

Fig. 5 SEM images of a) Reinforcement particles $\left(\mathrm{TiB}_{2}\right)$ b) Experiment 2 c) Experiment 3 d) Experiment 10

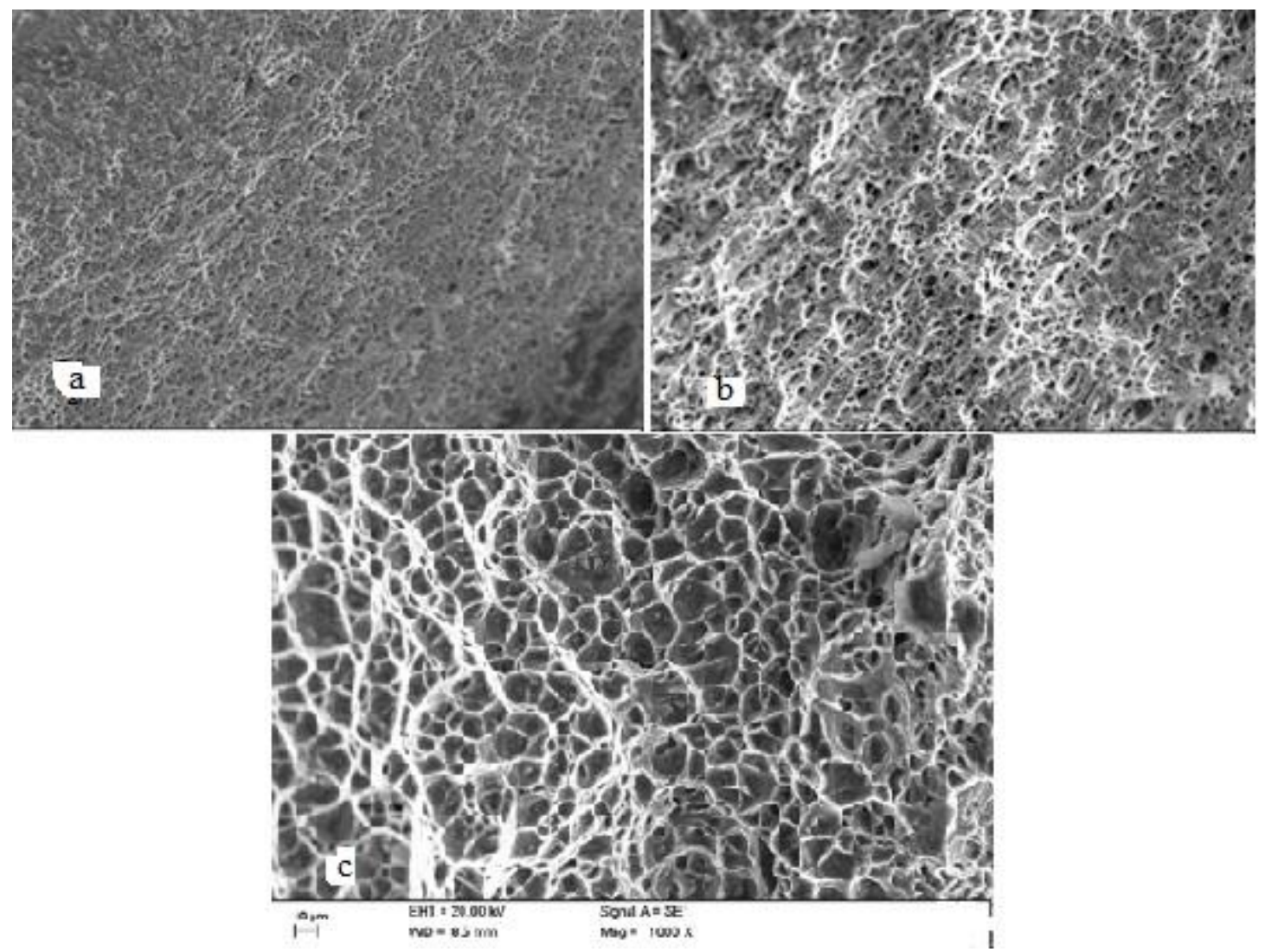

Fig. 6 Fractography of tensile specimens of a) base metal b) Exp. 2 c) Exp. 10

\section{Single response optimization using Taguchi method}

The Taguchi's technique is used for single response optimization. The Ultimate tensile strength (UTS), and Hardness were analysed to optimize the processing parameters. The larger 
the better criterion was selected for both responses to maximize responses. The $\mathrm{S} / \mathrm{N}$ ratio was calculated using the equation 1 and tabulated in the Table 5. The term Signal indicates the desirable value for output characteristic and Noise represents the undesirable value for the output.

$$
\frac{S}{N}=-10 \log _{10}\left(\frac{1}{n} \sum \frac{1}{y^{2}}\right)
$$

where $\mathrm{y}$ is the observed data and $\mathrm{n}$ is the no. of observations. The $\mathrm{S} / \mathrm{N}$ ratios and response table for all individual responses are shown in the Table 5. The mean $\mathrm{S} / \mathrm{N}$ ratio was estimated for four levels and process parameters which was presented in the Table 6 . Based on the mean response table of $\mathrm{S} / \mathrm{N}$ ratio, an optimal parameter for each parameter was identified with larger value of S/N ratio. The optimal parameters for UTS are speed of S3 (1400 rpm), feed of F3 (60 $\mathrm{m} / \mathrm{min}$ ), load L3 (6 N) and reinforcement R2 (4\%) and for hardness are speed of S3 (1400 rpm) , feed of F1 ( $20 \mathrm{~m} / \mathrm{min})$, load L1 (4 N) and reinforcement R3 (8\%). It has been found from response table that speed ranks first in the contribution of UTS next followed in the order of reinforcement, load and feed whereas Reinforcement ranks first and followed the reinforcement, speed, load and feed for hardness.

Table 5. Output characteristic and $\mathrm{S} / \mathrm{N}$ ratio

\begin{tabular}{lllll}
\hline Exp No. & UTS & Hardness & $\begin{array}{l}\text { S/N for } \\
\text { UTS }\end{array}$ & $\begin{array}{l}\text { S/N for } \\
\text { Hardness }\end{array}$ \\
\hline & & & & \\
1 & 231.570 & 103.823 & 47.2928 & 40.3257 \\
2 & 251.957 & 109.610 & 48.0251 & 40.7953 \\
3 & 268.473 & 116.167 & 48.5750 & 41.3011 \\
4 & 221.130 & 11.043 & 46.8908 & 40.9095 \\
5 & 256.660 & 122.177 & 48.1861 & 41.7391 \\
6 & 219.260 & 120.663 & 49.8190 & 41.6277 \\
7 & 298.460 & 108.213 & 49.4977 & 40.6849 \\
8 & 299.580 & 114.260 & 49.5299 & 41.1572 \\
9 & 307.323 & 128.030 & 49.7518 & 42.1461 \\
10 & 317.353 & 129.137 & 50.0301 & 42.2205 \\
11 & 314.553 & 117.840 & 49.9535 & 41.4256 \\
12 & 313.447 & 108.187 & 49.9228 & 40.6828 \\
13 & 301.687 & 115.190 & 49.5901 & 41.2277 \\
14 & 305.730 & 107.983 & 49.7064 & 40.6665 \\
15 & 285.447 & 118.107 & 49.1103 & 41.4451 \\
16 & 295.030 & 125.813 & 49.3970 & 41.9942 \\
& & & & \\
\hline
\end{tabular}

\subsection{Multi-response optimization using Grey Relational Analysis (GRA)}

The Grey Relational Analysis has been used for multi response optimization of any engineering problem. It gives effective solution to ambiguity, isolated multi input problems. The relationship between input and output responses ca be established by GRA method. The various steps involved in the GRA are normalization, data processing, grey coefficient and grey grade.

Normalization is a transformation performed on experimental data (input) to distribute evenly and scale it into acceptable range between zero and one for further analysis. 
Table 6. Response Table for S/N Ratio.

\begin{tabular}{c|cccc|cccc}
\hline Process & \multicolumn{4}{|c|}{ UTS } & \multicolumn{5}{c}{ Hardness } \\
$\begin{array}{c}\text { parameter } \rightarrow \\
\text { Level } \downarrow\end{array}$ & $\mathrm{S}$ & $\mathrm{F}$ & $\mathrm{L}$ & $\mathrm{R}$ & $\mathrm{S}$ & $\mathrm{F}$ & $\mathrm{L}$ & $\mathrm{R}$ \\
\hline 1 & 47.70 & 48.71 & 48.37 & 49.37 & 40.83 & $\mathbf{4 1 . 3 6}$ & $\mathbf{4 1 . 3 4}$ & 40.59 \\
2 & 48.51 & 48.65 & 48.81 & $\mathbf{4 9 . 2 7}$ & 41.30 & 41.33 & 41.17 & 41.15 \\
3 & $\mathbf{4 9 . 9 1}$ & $\mathbf{4 9 . 2 8}$ & $\mathbf{4 9 . 3 9}$ & 49.05 & $\mathbf{4 1 . 6 2}$ & 40.21 & 41.32 & $\mathbf{4 1 . 8 1}$ \\
4 & 49.45 & 48.94 & 48.00 & 48.14 & 41.33 & 41.19 & 41.26 & 41.53 \\
Delta (Max.- & 2.22 & 0.64 & 1.03 & 1.13 & 0.79 & 1.15 & 0.17 & 1.12 \\
Min) & & & & & & & & \\
Rank & 1 & 4 & 3 & 2 & 2 & 4 & 3 & 1 \\
\hline
\end{tabular}

The objective is to maximize response, then Higher the Better criteria is used to normalize the reference sequence using eq. (2).

$$
x_{i}^{*}(k)=\frac{x_{i}^{0}(k)-\min x_{i}^{0}(k)}{\max x_{i}^{0}(k)-\min x_{i}^{0}(k)}
$$

where $\mathrm{x}_{\mathrm{i}}{ }^{*}(\mathrm{k})$ is the value after grey relational generation, $\min \mathrm{x}_{\mathrm{i}}^{0}(\mathrm{k})$ is the smallest value of $\mathrm{x}_{\mathrm{i}}$ ${ }^{0}(\mathrm{k})$ for $\mathrm{k}$ th response, $\max x \mathrm{xi}^{0}(\mathrm{k})$ is the largest value of $\mathrm{x}_{\mathrm{i}}{ }^{0}(\mathrm{k})$ for $\mathrm{k}$ th response. the number of experiments $(\mathrm{i}=1,2,3 \ldots)$ and the number of responses $(\mathrm{k}=1,2,3 \ldots)$. Data pre-processing was performed on basic data for all experimental values. The grey relational coefficient is calculated using the eq. (3).

$$
\xi_{i}(k)=\frac{\Delta_{\min }+\zeta \Delta_{\max }}{\Delta_{0 i}(k)+\zeta \Delta_{\max }}
$$

The deviation sequence $\Delta_{0 i}(k)=\left\|x_{0}^{*}(k)-x_{i}^{*}(k)\right\|$ is calculated by taking the absolute difference between the reference sequence $\mathrm{x}_{0} *(\mathrm{k})$ and the comparability sequence $\mathrm{x}_{\mathrm{i}} *(\mathrm{k})$. The reference is generally taken as 1 and $\mathrm{x}_{0} *(\mathrm{k})$ is the comparability sequence. $\zeta$ is distinguished coefficient 0.5 is generally used. $\Delta_{\min }=\min _{\forall j \in i \forall k} \min \left\|x_{0}^{*}(k)-x_{i}^{*}(k)\right\| \quad \&$ $\Delta_{\max }=\max _{\forall j \in i \forall k} \max _{\|}\left\|x_{0}^{*}(k)-x_{i}^{*}(k)\right\|$. The normalized values of responses and deviational sequence of performance characteristics are tabulated in the Table 7 . The overall Grey relational grade is computed by taking the average of the grey relational coefficients corresponding to each performance characteristic and calculated by using the following eq. (4).

$$
\gamma_{i}=\frac{1}{n} \sum_{k=1}^{n} \xi_{i}(k)
$$

where $\mathrm{n}$ number of experiments. The relational grades are tabulated in the Table 8 .

Based on the grey grade, the highest value of grade was ranked 1 for experiment 10 and mean response of the parameters was calculated and tabulated in the Table 9. The highest value of mean response of parameters and levels was the optimal parameter. The optimal parameters for UTS and Hardness are speed S3 (1400 rpm), feed F3 (40 m/min), load L3 (6 N) and reinforcement R3 (8\%). It has been found from response Table 9 that the speed ranks first in the contribution of UTS and hardness next followed in the order of reinforcement, load .The predicted UTS and Hardness value (from the equation) are $320.29 \mathrm{MPa}$ and $128.68 \mathrm{Hv}$ respectively and confirmation experiments was done values are with less than $10 \%$ variation.

\subsection{Analysis of Variance (ANOVA)}

The Taguchi experiment method could not judge the effect of individual parameters on the entire process as it gives most predominant parameters. The purpose of the ANOVA is to 
Table 7. Normalized values and Deviational sequence of response characteristics.

\begin{tabular}{ccc|cc}
\hline Exp. No. & $\begin{array}{c}\text { Normalized values of Response } \\
\text { characteristics }\end{array}$ & \multicolumn{2}{c}{$\begin{array}{c}\text { Deviational Sequence of } \\
\text { Response characteristic after } \\
\text { data processing }\end{array}$} \\
& UTS & Hardness & UTS & Hardness \\
\hline Ref. Seq. & 1.000 & 1.000 & 1.000 & 1.000 \\
& & & & \\
$\mathbf{1}$ & 0.1254 & 0.0000 & 0.8746 & 1.0000 \\
$\mathbf{2}$ & 0.3298 & 0.2287 & 0.6702 & 0.7713 \\
$\mathbf{3}$ & 0.4982 & 0.4875 & 0.5018 & 0.5128 \\
$\mathbf{4}$ & 0.0156 & 0.2862 & 0.9844 & 0.5138 \\
$\mathbf{5}$ & 0.3781 & 0.7487 & 0.6219 & 0.2513 \\
$\mathbf{6}$ & 0.0000 & 0.6654 & 1.000 & 0.3346 \\
$\mathbf{7}$ & 0.8039 & 0.1734 & 0.1961 & 0.8246 \\
$\mathbf{8}$ & 0.8153 & 0.4124 & 0.1847 & 0.5876 \\
$\mathbf{9}$ & 0.8942 & 0.9565 & 0.1052 & 0.0435 \\
$\mathbf{1 0}$ & 1.000 & 1.0000 & 0.0000 & 0.0000 \\
$\mathbf{1 1}$ & 0.9714 & 0.5539 & 0.0286 & 0.4461 \\
$\mathbf{1 2}$ & 0.9601 & 0.1722 & 0.0399 & 0.8278 \\
$\mathbf{1 3}$ & 0.8402 & 0.4492 & 0.1598 & 0.5508 \\
$\mathbf{1 4}$ & 0.8815 & 0.1643 & 0.1185 & 0.8357 \\
$\mathbf{1 5}$ & 0.6747 & 0.5642 & 0.3253 & 0.4358 \\
$\mathbf{1 6}$ & 0.7724 & 0.8688 & 0.2274 & 0.1312 \\
& & & & \\
& & & &
\end{tabular}

Table 8. The Grey Relational Grade

\begin{tabular}{ccccc}
\hline & \multicolumn{2}{c}{ Grey Relational Grade } & & \\
\cline { 2 - 3 } Exp. No. & & & Grey Grade & Rank \\
& UTS & Hardness & & \\
\hline 1 & 0.3637 & 0.3333 & 0.3485 & 16 \\
2 & 0.4272 & 0.3932 & 0.4321 & 15 \\
3 & 0.4991 & 0.4936 & 0.4961 & 11 \\
4 & 0.3368 & 0.4931 & 0.4149 & 14 \\
5 & 0.4456 & 0.6555 & 0.5555 & 9 \\
6 & 0.3333 & 0.5990 & 0.4661 & 12 \\
7 & 0.7182 & 0.3774 & 0.5478 & 10 \\
8 & 0.7302 & 0.4597 & 0.5949 & 7 \\
9 & 0.8261 & 0.9197 & 0.8726 & 2 \\
10 & 1.0000 & 1.0000 & 1.000 & 1 \\
11 & 0.9458 & 0.5284 & 0.7371 & 3 \\
12 & 0.9260 & 0.3765 & 0.6512 & 4 \\
13 & 0.7578 & 0.4758 & 0.6168 & 5 \\
14 & 0.8084 & 0.3743 & 0.5913 & 8 \\
15 & 0.6058 & 0.5343 & 0.4695 & 13 \\
16 & 0.6873 & 0.7921 & 0.6014 & 6 \\
\hline
\end{tabular}


Table 9. Grey Response Table for S/N Ratio.

\begin{tabular}{lllll}
\hline $\begin{array}{l}\text { Process } \\
\text { parameter } \rightarrow \\
\text { Level } \downarrow\end{array}$ & Speed & Feed & Load & Reinforcement \\
\hline Level 1 & 0.4229 & 0.5983 & 0.5382 & 0.5347 \\
Level 2 & 0.5410 & $\mathbf{0 . 6 2 2 3}$ & 0.5270 & 0.5952 \\
Level 3 & $\mathbf{0 . 8 1 5 2}$ & 0.5626 & 0.6387 & $\mathbf{0 . 6 6 3 2}$ \\
Level 4 & 0.5697 & 0.5656 & $\mathbf{0 . 6 4 4 8}$ & 0.5557 \\
Delta & 0.3923 & 0.0597 & 0.1178 & 0.1285 \\
Rank & 1 & 4 & 3 & 2 \\
\hline
\end{tabular}

Table 10 Analysis of variance (ANOVA)

\begin{tabular}{lllllll}
\hline $\begin{array}{l}\text { Process } \\
\text { parameter }\end{array}$ & $\begin{array}{l}\text { Degrees } \\
\text { of }\end{array}$ & $\begin{array}{l}\text { Sum of } \\
\text { square }\end{array}$ & $\begin{array}{l}\text { Adjusted } \\
\text { sum of }\end{array}$ & F-value & P- Value & $\begin{array}{l}\text { Percentage } \\
\text { contribution }\end{array}$ \\
& Freedom & (SS) & square & & &
\end{tabular}

A) For UTS

\begin{tabular}{lllllll} 
Speed & 3 & 11472 & 3824.0 & 7.58 & 0.004 & $65.45 \%$ \\
Feed & 3 & 862.77 & 2876 & 0.21 & 0.890 & $4.92 \%$ \\
Load & 3 & 1943 & 647.8 & 0.50 & 0.690 & $11.09 \%$ \\
$\%$ & 3 & 2742 & 914.1 & 0.74 & 0.547 & $15.65 \%$ \\
reinforcement & & & & & & \\
Error & 12 & 6055 & 1.195 & -- & -- & $2.89 \%$ \\
Total & 15 & 17525 & -- & -- & -- & $100.00 \%$ \\
\hline
\end{tabular}

B) Hardness

\begin{tabular}{lllllll} 
Speed & 3 & 231.3 & 77.10 & 1.42 & 0.286 & $26.15 \%$ \\
Feed & 3 & 18.58 & 6.192 & 0.09 & 0.966 & $2.16 \%$ \\
Load & 3 & 14.57 & 4.858 & 0.07 & 0.966 & $1.65 \%$ \\
$\%$ & 3 & 595.53 & 198.44 & 8.23 & 0.003 & $67.30 \%$ \\
reinforcement & & & & & & \\
Error & 12 & 653.3 & 72.506 & & & $2.74 \%$ \\
Total & 15 & 884.6 & & & & $100.00 \%$ \\
\hline
\end{tabular}

identify the effect of individual parameter on the output responses. Analysis of variance(ANOVA) has been calculated to investigate the significance of input parameters. The percentage contribution of each process parameter on the total variation was estimated with ratio of SS of corresponding parameter to total SS. The F-test and P test were used to determine which process has a significant effect on output responses. Usually, the change of the process parameter has a significant effect on the quality characteristics, when $F$ is large and $\mathrm{P}$ value is smaller. The results of ANOVA were presented in Table 10. The speed has $65.45 \%$ contribution in the output response for UTS followed by load, \% reinforcement and feed whereas percentage reinforcement of contributed highest value of $67.30 \%$ reinforcement followed by speed, feed and load for respectively. 


\subsection{VALIDATION OF RESULTS.}

The optimal value of taguchi and grey method is estimated from the equation (5).

$$
{ }^{\mathrm{\gamma}} \text { predicted }={ }^{\mathrm{\gamma}} \mathrm{m}+n \sum_{i=0}^{n=16}\left({ }^{\mathrm{i}} \mathrm{i}-{ }^{\mathrm{\gamma}} \mathrm{m}\right)
$$

where ${ }^{\mathrm{r}} \mathrm{m}$ is the mean of the response, $\mathrm{n}$ is the number of experiments, ${ }^{{ }} \mathrm{i}$ is the value at mean level for optimal parameter. The optimum level of the process parameters is the level with the highest S/N ratio and high grey relational grade and predicted the optimal values for UTS and Hardness. The confirmation was carried out by taking the optimal process parameters. The tested mechanical properties are less than $10 \%$ variation.

Table 11. Validation of Optimal Results

\begin{tabular}{|c|c|c|c|}
\hline Quality Characteristic & Optimal Parameters & $\begin{array}{l}\text { Predicted } \\
\text { Value }\end{array}$ & $\begin{array}{l}\text { Experimental } \\
\text { Value }\end{array}$ \\
\hline $\begin{array}{l}\text { 1. Taguchi Optimization for } \\
\text { UTS(MPa) }\end{array}$ & $\begin{array}{l}\text { Speed }=1400 \mathrm{rpm}, \\
\text { Feed }=60 \mathrm{~mm} / \mathrm{min} \\
\text { Load }=6 \mathrm{~N} \\
\text { Reinforcement }=4 \%\end{array}$ & $350.70 \mathrm{MPa}$ & $319.48 \mathrm{MPa}$ \\
\hline $\begin{array}{l}\text { 2. Taguchi optimization for } \\
\text { Hardness }(\mathrm{Hv})\end{array}$ & $\begin{array}{l}\text { Speed }=1400 \mathrm{rpm}, \\
\text { Feed }=60 \mathrm{~mm} / \mathrm{min}, \\
\text { Load }=6 \mathrm{~N} \\
\text { Reinforcement }=4 \%\end{array}$ & $130.13 \mathrm{Hv}$ & $126.86 \mathrm{Hv}$ \\
\hline 3. Grey Analysis for UTS & $\begin{array}{l}\text { Speed }=1400 \mathrm{rpm}, \\
\text { Feed }=40 \mathrm{~mm} / \mathrm{min}, \\
\text { Load }=7 \mathrm{~N} \\
\text { Reinforcement }=8 \%\end{array}$ & $320.29 \mathrm{MPa}$ & $318.84 \mathrm{MPa}$ \\
\hline $\begin{array}{l}\text { 4rey Analysis for } \\
\text { Hardness }\end{array}$ & $\begin{array}{l}\text { Speed = } 1400 \mathrm{rpm}, \\
\text { Feed }=40 \mathrm{~mm} / \mathrm{min}, \\
\text { Load }=7 \mathrm{~N} \\
\text { Reinforcement }=8 \%\end{array}$ & $128.68 \mathrm{Hv}$ & $132.71 \mathrm{Hv}$ \\
\hline
\end{tabular}

\section{Conclusion}

The AA 6061/TiB 2 metal matrix composite was successfully fabricated via friction stir processing. The mechanical properties like tensile strength and hardness were evaluated. The micro structure observations showed the homogeneous distribution of particles. The process parameters were optimized towards tensile strength and hardness using taguchi technique and grey analysis. The optimal process parameters were estimated and confirmation experiments were conducted and lies within the $10 \%$ predicted value. The ANOVA results indicates that rotational speed found to be most influential process parameter with $65.45 \%$ followed by reinforcement $(24.35 \%)$, load $(23 \%)$ and feed $(22 \%)$ of the tool are highly significant.

\section{REFERENCES}

[1] H. Bakes, D. Benjamin, C.W. Kirkpatrick. Metals handbook, vol. 2. OH: ASM. Metals Park, 1979, 3 - 23.

[2] E.M. Sharifi, F. Karimzadeh, M.H. Enayati, Fabrication and Evaluation of mechanical and tribological properties of boron carbide reinforced aluminum matrix Nano composites. Materials and Design, 2011 (32), No. 6, 3263 - 3271. 
[3] M. Salehi, H. Farnoush, J. Aghazadeh Mohandesi. Fabrication and characterization of functionally graded $\mathrm{Al}-\mathrm{SiC}$ nano composite by using a novel multistep friction stir processing. Materials and Design, 2014 (63), 419 - 426.

[4] S.K. Chaudhury, S.C. Panigrahi. Role of processing parameters on microstructural evolution of spray formed $\mathrm{Al}-2 \mathrm{Mg}$ alloy and $\mathrm{Al}-2 \mathrm{Mg}-\mathrm{TiO} 2$ composite. Journal of Material Processing Technology, 2007 (182), 343 - 351.

[5] F. Akhlaghi, A. Zare-Bidaki. Influence of graphite content on the dry sliding and oil impregnated sliding wear behaviour of Al 2024-graphite composites produced by in situ powder metallurgy method, Journal of Wear, 2009 (266), No. 1-2,2009, 37- 45.

[6] A. Baradeswaran, A. Elaya Perumal. Influence of B4C on the tribological and mechanical properties of Al 7075-B4C composites", Composites B, 2013 (54), 146 152 .

[7] A. Kumar, S. Lal, S. Kumar. Fabrication and characterization of A359/A12O3 metal matrix composite using electromagnetic stir casting method. Journal of Material Research Technology, 2013 (2), No. 3, 250 - 254.

[8] P. Sharma, S. Sharma, D. Khanduja. Production and some properties of Si3N4 reinforced aluminium alloy composites. Journal of Asian Ceramic Societies, 2015 (3), 352-359.

[9] A. Kalkanli, S. Yilmaz. Synthesis and characterization of aluminium alloy 7075 reinforced with silicon carbide particulates, Materials and Design, 2008 (29), No. 4, $775-780$.

[10] M. Zhao, G. Wu, Z. Dou, L. Jiang. TiB $2 \mathrm{P} / \mathrm{Al}$ composite fabricated by squeeze casting technology. Material Science. Engineering A. 2004 (374), No. 1 - 2, 303-306

[11] L. Ceschini, G. Minak, A. Morri. Tensile and fatigue properties of the AA6061/20 vol.\% Al2O3p and AA7005/10 vol.\% Al2O3p composites. Composites Science and Technology, 2006 (66), 333 - 342.

[12] K. B. Lee, J. P. Ahn, H. Know. Characteristics of AA6061/BN Composite Fabricated by Pressure Less Infiltration Technique. Metallurgical and materials transactions A, 2001 (32), 1007 - 1018.

[13] C. Bacciarini, V. Mathier. Aluminium AA6061 Matrix Composite Reinforced with Spherical Alumina Particles Produced by Infiltration: Perspective on Aerospace Applications", Journal of Metallurgy, 2014, Article ID 248542, 10 pages.

[14] S.K. Ghosh, P. Saha. Crack and wear behaviour of Sic particulate reinforced aluminium based metal matrix composite fabricated by direct metal laser sintering process. Materials Design, 2011 (32), 139 - 45.

[15] K. L. Tee, L. Lu, M. O. Lai. Wear performance of in situ Al- TiB 2 composite", Wear, 2000 (240), $59-64$.

[16] H. S. Arora, H. Singh, B. K. Dhindaw. Composite fabrication using friction stir processing - A review. International Journal of Advanced Manufacturing Technology, 2012 (61), No. 9 - 12, 1043 - 1055.

[17] Y. M. Youssef, R. J. Dashwood, P. D. Lee. Effect of clustering on particle pushing and solidification behaviour in TiB2 reinforced aluminium PMMCs. Composites Part A: Applied Science and Manufacturing, 2005 (36), 747 - 769. 
[18] L. T. Jiang, G. Q. Chen, X. D. He, M. Zhao, Z. Y. Xiu, R. J. Fan, G. H. Wu. Microstructure and tensile properties of TiB2p/6061 Al composites. Transactions of Nonferrous Metals Society of China, 2009 (19), Supplement 3, s542 - s546.

[19] V. Umasankar, M. Anthony Xavior, S. Karthikeyan. Experimental evaluation of the influence of processing parameters on the mechanical properties of Sic particle reinforced AA6061 aluminium alloy matrix composite by powder processing. Journal of Alloys and Compounds, 2014 (582), No. 9, 380 - 386.

[20] M. Thomas, E. D. Nicholas, J. C. Needham, M. G. Murch, P. Temple Smith, C. J. Dawes, The Welding Institute, TWI, International Patent Application No. PCT/GB92/02203 and GB Patent Application No. 9125978.8, 1991.

[21] R.S. Mishra, Z.Y. Ma, I. Charit. Friction stir processing: A novel technique for fabrication of surface composite. Journal of material science and engineering, 2003 (341), No. 1 - 2, 307 - 310.

[22] R. Jančo, L. Écsi, P. Élesztős. Fsw numerical simulation of aluminium plates by sysweld - PART II. Journal of mechanical engineering - Strojnícky časopis, 2016 (66), No. 2, $29-36$.

[23] R. Jančo, L. Écsi, P. Élesztős. Fsw numerical simulation of aluminium plates by sysweld - PART I. Journal of mechanical engineering - Strojnicky časopis, 2016 (66), No. 1, 47 -52 .

[24] W. Wang, Q. Shi, P. Liu, H. Li, T. Li. A novel way to produce bulk SiCp reinforced aluminium metal matrix composites by friction stir processing, Journal of Materials Processing Technology, 2009 (209), No. 4, 2099 - 2103.

[25] A. Handa, V. Chawla. Experimental evaluation of mechanical properties of friction welded dissimilar steels under varying axial pressures. Journal of mechanical engineering - Strojnícky časopis, 2016 (66), No. 1, 27 - 36.

[26] S. Soleymani, A. Abdllah - Zadesh, S.A. Alodkht. Micro structural and tribological properties of Al 583 based surface hybrid composite produced by friction stir processing. Wear, 2012 (278 - 279), 41-47.

[27] A. Dolatkhah, P. Golbabaei, M. K. Besharat, G, F. Molaikiya. Investigating effects of process parameters on micro structure and mechanical properties of Al 5052/Sic metal matrix composite fabricated via friction stir processing, Materials and Design, 2012 (37), $458-464$.

[28] J. Gandra, R. Miranda, P. Vilaca, A. Velhinho, J. P. Teixeira. Functionally graded materials produced by friction stir processing, Journal of Materials Processing Technology, 2011 (211), No. 11, 1659 - 1668.

[29] A. Kurt, et.al. Surface modification of aluminum alloys by friction stir processing, Journal of material processing technology, 2011 (211), 313 - 331.

[30] S. R. Anvari, F. Karimzadeh, M. H. Enayati. Wear characteristics of Al-Cr-O surface nano-composite layer fabricated on A16061 plate by friction stir processing. Wear, 2013 (304), $144-151$.

[31] M. Yang, X. Chengying, Ch. Wu, K. Lin , J. Ch. Yuh, L. Anal. Fabrication of AA6061 / Al2o3 nano ceramic particle reinforeced composite coating by using friction stir processing. Journal Material Science, 2010 (45), 4431 - 4438. 
[32] A. Thangarasu, N. Murugan, I. Dinaharan, S. J. Vijay. Synthesis and characterization of titanium carbide particulate reinforced AA6082 aluminium alloy composites via friction stir processing. Archives of Civil and Mechanical Engineering, 2015 (15), No. 2, 324 334.

[33] Y. Morisada, H. Fujii, T. Nagaoka, K. Nogi, M. Fukusumi. Fullerene/A5083 composites fabricated by material flow during friction stir processing", Composites: Part A, 2007 (38), $2097-2101$.

[34] D. C. Montgomery. Design and analysis of experiments [M]. IV Edition. NY: JohnWiley \& Sons, Inc, 2006.

[35] P. J. Taguchi techniques for quality engineering: loss function, orthogonal experiments, parameter and tolerance design. New York: NY: McGraw-Hill Professional; 2nd edition, 1995.

[36] E. R. I Mahmoud, M. Takahashi, T. Shibayanagi, K. Ikeuchi. Effect of friction stir processing tool probe on fabrication of $\mathrm{SiC}$ particle reinforced composite on aluminium surface. Science and Technology of Welding and Joining, 2009 (14), No. 5, 713 - 725.

[37] W. Wang, Q. Shi, P. Liu, H. Li, T. Li. A novel way to produce bulk SiCp reinforced aluminium metal matrix composites by friction stir processing. Journal of Materials Processing Technology, 2009 (209), No. 4, 2099 - 2103.

[38] M. Salehi, M. Saadatmand, J. Aghazadeh Mohandesi. Optimization of process parameters for producing AA6061/SiC nanocomposites by friction stir processing. Transactions Nonferrous Metals Society of China, 2012 (22), 1055 - 1063

[39] M. Barmouz, M. K. B. Givi, J. Seyfi. On the role of processing parameters in producing $\mathrm{Cu} / \mathrm{SiC}$ metal matrix composites via friction stir processing: Investigating microstructure, micro hardness, wear and tensile behaviour. Materials Characterization, 2011 (62), No. 1, 108 - 117.

[40] J. Deng. Introduction to grey system. J Grey Systems, 1989, 1 - 24.

[41] J. Kundu, H. Singh, Friction stir welding: multi-response optimization using Taguchibased GRA, Production \& Manufacturing Research, 2016 (4), No. 1, 228 - 241.

[42] S. Vijayan, R. Raju, S. R. K Rao. Multiobjective Optimization of Friction Stir Welding Process Parameters on Aluminium Alloy AA 5083 Using Taguchi-Based Grey Relation Analysis. Materials and Manufacturing Processes, 2010 (25), No. 11, 1206 - 1212.

[43] S. Kasman. Multi response optimization using the Taguchi based grey relational analysis, a case study for dissimilar stir butt welding of AA6082 -T6 /AA5754-H111, The international journal of Advanced manufacturing technology, 2013 (68), 795 - 804.

[44] Ch.-H. Chien, W-B Lin, T. Chen. Optimal FSW process parameters for aluminum alloys AA5083. Journal of the Chinese Institute of Engineers, 2011 (34), No. 1, 99 - 105.

[45] S. Vijayan, R. Raju, S. R. K Rao. Multiobjective Optimization of Friction Stir Welding Process Parameters on Aluminium Alloy AA 5083 Using Taguchi-Based Grey Relation Analysis. Materials and Manufacturing Processes, 2010 (25), No. 11, 1206 - 1212.

[46] N. D. Ghetiya, K.M. Patel, A.J. Kavar. Multi-objective optimization of FSW process parameters of aluminum alloy using taguchi-based grey relational analysis. Transactions of the Indian Institute of Metals, 2016 (69), 917 - 923. 
[47] M.M. El-Rayes, E.A. El-Danaf. The influence of multi-pass friction stir processing on the microstructural and mechanical properties of Aluminum Alloy6082. Journal of Material Processing Technology, 2012 (212), 1157 - 1168.

[48] A. Hamdollahzadeha, M. Bahrami, M. Farahmand Nikoo, A. Yusefi , M.K. Besharati Givib, N. Parvina. Microstructure evolutions and mechanical properties of nano-SiCfortified AA7075 friction stir weldment: The role of second pass processing. Journal of Manufacturing Processes, 2015 (20), No. 1, 367 - 373.

[49] M. Barmouz, P. Asadi, M. K. B. Givi, M. Taherishargh. Investigation of mechanical properties of $\mathrm{Cu} / \mathrm{SiC}$ composite fabricated by FSP: effect of SiC particles' size and volume fraction", Material Science and Engineering A, 2011 (528), No. 3, 1740 - 1751.

[50] D.K. Lim, T. Shibayanagi, P.A. Gerlich. Synthesis of multi-walled CNT reinforced aluminium alloy composite via friction stir processing. Materials Science and Engineering A., 2009 (507), No. 1 - 2, 194 - 199.

[51] L. Suvarna Raju, A. Kumar. Influence of $\mathrm{Al}_{2} \mathrm{O}_{3}$ particles on the microstructure and mechanical properties of copper surface composites fabricated by friction stir processing. Defence Technology, 2014 (10), 375 - 383. 
